\title{
"VOCÊ É UMA RAINHA": CANTORAS NEGRAS E SUAS AUTORREPRESENTAÇÕES DE RAINHAS EM VIDEOCLIPES
}

"YOU ARE A QUEEN": BLACK SINGERS AND YOUR SELF - REPRESENTATION QUEENS IN MUSIC VIDEOS

\section{"ERES UMA REINA": CANTANTES NEGRAS Y SU REINA AUTO REPRESENTÁCION EM VIDEOS MUSICALES}

\author{
Sandra Rita de Cássia Roza ${ }^{1}$
}

\section{RESUMO}

Este artigo visa analisar 5 videoclipes em que cantoras negras nacionais e internacionais se vestem ou se afirmam como rainhas: "Menina Pretinha", Mc Soffia; “Ouça-me Rmx", Tássia Reis; "É o poder”, Karol Conká; "Moment 4 Life", Nicki Minaj e "Love on the brain", Rihanna. A fim de entender o motivo dessas cantoras de se auto representarem e se afirmarem como mulheres da realeza, foi realizada uma análise do discurso para observar e analisar o que poderia está implícito e explícito nas produções. A partir da análise, foi possível perceber que artistas propõem outras representações sobre mulheres negras, questionam uma posição de poder e trazem representatividade para outras meninas e mulheres negras na realeza.

PALAVRAS-CHAVE: Representatividade. Rainhas negras. Videoclipes. Cantoras negras.

\section{ABSTRACT}

This article aims to analyze 5 music videos in which national and international black singers dress or claim to be queens: "Little Black Girl", Mc Soffia; "Listen to me Rmx", Tássia Reis; "It is the power," Karol Conká; "Moment 4 Life" by Nicki Minaj and "Love on the Brain" Rihanna. In order to understand why these singers self-represent and affirm themselves as royal women, an analysis of the discourse was performed to observe and analyze what could be implicit and explicit in the productions. From the analysis, it was possible to see that artists propose other representations of black women, question a position of power and bring representativeness to other black girls and women in royalty.

Submetido em: 30/07/2019 - Aceito em: 02/12/2019 - Publicado em: 28/12/2019.

${ }^{1}$ Universidade Federal de Ouro Preto (UFOP)/Brasil. Graduada em Jornalismo pela Universidade Federal de Ouro Preto (UFOP). Tem experiência na área de Comunicação, com ênfase em Jornalismo e Assessoria de Comunicação Institucional. Pesquisa gênero e raça em representações midiáticas voltadas para o público infantil, como filmes, desenhos animados, livros e telenovela. 
KEYWORDS: Representativity. Black queens. Music videos. Black singers.

\section{RESUMEN}

Este artículo tiene como objetivo analizar 5 videos musicales en los que cantantes negras nacionales e internacionales se visten o dicen ser reinas: "Little Black Girl", Mc Soffia; "Escúchame Rmx", Tássia Reis; "Es el poder", Karol Conká; "Moment 4 Life" de Nicki Minaj y Rihanna "Love on the Brain". Para entender por qué estas cantantes se representan a sí mismas y se afirman como mujeres reales, se realizó un análisis del discurso para observar y analizar lo que podría ser implícito y explícito en las producciones. A partir del análisis, fue posible ver que los artistas proponen otras representaciones de mujeres negras, cuestionan una posición de poder y brindan representatividad a otras niñas y mujeres negras en la realeza.

PALABRAS CLAVE: Represenatividad. Reinas negras. Video musicales. Cantantes negras.

\section{INTRODUÇÃO}

Desde criança, eu me perguntava o porquê de não haver uma princesa ou uma rainha negra nos desenhos animados e nos livros infantis. Quando perguntava a um adulto, principalmente as professoras na escola, elas falavam que não haviam princesas nem rainhas negras. Eu não acreditava e perguntava outras pessoas. Algumas respondiam o mesmo que as professoras. Outras diziam que não sabiam o porquê e algumas até diziam que para ser uma princesa a menina tinha que ser "muito linda", igual a dos filmes da Disney. Entretanto, nenhuma dessas respostas era suficiente para mim, eu queria entender o porquê. Então, cresci e fui cursar jornalismo na Universidade Federal de Ouro Preto (UFOP) e, novamente, no $6^{\circ}$ semestre me veio o porquê de não haver uma princesa negra. Assim, realizei o meu Trabalho de Conclusão de Curso (TCC) sobre a Princesa Tiana (do Filme “A princesa e o sapo" - 2009), a primeira princesa negra de animação dos Estúdios Disney. Agora, eu já via ali uma princesa negra, o que me dava uma sensação de representatividade ao mesmo tempo que reforçava a subalternidade da mulher negra, percebi que era importante problematizar isso também e buscar as respostas para a minha dúvida. Consegui, mas ainda continuo observando a representatividade e a ausência de mulheres negras na realeza, principalmente nas produções audiovisuais. Dessa forma, tenho percebido alguns videoclipes de cantoras negras (nacionais e internacionais) que se vestem ou se afirmam como rainhas em suas músicas. Assim, esse presente artigo buscar analisar essas produções a fim de apresentar o que essas cantoras dizem 
e questionam e como isso pode ser uma das referências para mulheres e meninas negras sobre princesas e rainhas negras, visto que videoclipes musicais possuem alcances nacionais e internacionais.

\title{
Ser ver e se reconhecer: construção das identidades
}

Zygmunt Bauman (2005) aborda a necessidade de não se conceituar definitivamente a palavra identidade. Ele não tenta definir identidade, mas propõe refletir sobre os contextos sociais, políticos e culturais em que essa palavra está inserida para, a partir daí, desenvolver relações que podem ajudar a refletir sobre o que é identidade, mas não delimitá-la. Ainda conforme Bauman, a globalização também interfere nas identidades, o que dificulta ainda mais denominar e limitar o termo. Nesse sentido,

\begin{abstract}
o pertencimento" e a "identidade" não tem a solidez de uma rocha, não são garantidos para toda a vida, são bastantes negociáveis e revogáveis e de que as decisões que o próprio indivíduo toma, os caminhos que percorre, a maneira como age e a determinação de se manter firme a tudo isso são fatores cruciais tanto para o "pertencimento" quanto para a "identidade". (p. 17-18)
\end{abstract}

Dessa forma, o autor argumenta que a identidade que alguém tem hoje pode não ser a mesma de daqui um tempo, assim também a ideia de pertencimento que ela possui, seja de grupo identitário ou local, por exemplo. Além disso, Bauman aborda que uma pessoa pode ter várias identidades, com o exemplo de sua amiga Agnes Heller que: "uma vez se queixou de que, sendo mulher, húngara, judia, norte-americana e filósofa, estava sobrecarregada de identidades demais para uma pessoa.” (p.19)

Vale ressaltar também que o processo de se reconhecer ou partilhar algo em comum com um grupo, também interfere nas construções identitárias de cada indivíduo. Para Marcio Serelle e Ercio Sena (2018), “as experiências de reconhecimento intersubjetivo formam as identidades individuais e de grupo." (p. 5). Os autores ainda discutem que o processo de reconhecimento individual acontece diante outros grupos: 
O indivíduo não possui identidade isoladamente, mas apenas quando é posto em relação com um outro e reconhecido em suas capacidades e propriedades, ele passa a conhecer os aspectos constituintes de sua particularidade, que o levam à compreensão de sua individualidade e ao autorreconhecimento. (2018, p. 5)

Em vista disso, é válido perceber que, de certa forma, o processo de construção e escolhas de identidades passa também pelo reconhecimento, ou melhor, pelo sentimento de reconhecimento que pode contribuir para o processo de representatividade, por exemplo. Além do mais, o processo de representatividade não é absoluto e pode corresponder a uma ou algumas das identidades do indivíduo, pois como afirma o Bauman podemos ter várias identidades.

\section{Mídia, Racismo e Representação}

Ao se falar em mídia, devemos olhar para as questões e processos que a envolve e, principalmente, para as ideologias que ela possui que reforçam os racismos. De acordo com Muniz Sodré (1999),

A mídia funciona no nível macro como um gênero discursivo capaz de catalisar expressões políticas e institucionais sobre as relações inter-raciais, em geral estruturadas por uma tradição intelectual elitista que, de uma maneira ou de outra, legitima a desigualdade social pela cor da pele.” (p.243)

Essa desigualdade social pode ser percebida nas representações de personagens negras em telenovelas em que, na maioria das vezes, elas realizam papéis subalternos. Por exemplo, a personagem Raquel (Érika Januza), da telenovela O outro lado do paraíso (2017-2018), da Rede Globo, que embora seja uma juíza, no início da trama, foi uma empregada doméstica em uma família racista. (ROZA, 2018, p. 1). Para Danubia Fernandes (2009),

A insistente representação do negro em papéis subalternos e serviçais reforça a idéia de sua inferioridade intelectual, desvinculando - o das posições de poder dentro da sociedade brasileira." (FERNANDES, p.50) 


\section{Revista Docência e Cibercultura}

Desse modo, Sodré contextualiza que o Grupo de Assessoria e Participação do Governo do Estado de São Paulo (GAP), em 1982, tinha o objetivo de realizar a esterilização de mulheres negras (pretas e pardas) devido ao "crescimento da população escura e que isto tendencialmente resultaria na ocupação do poder político por afrodescendentes.” (1999, p. 234). Aqui, fica evidente que a elite brasileira, constituída em grande parte por homens brancos e ricos, temia um Brasil negro e com negros no poder, o que também evidencia o racismo estrutural.

Além disso, ao pensar as questões raciais, Lia Schucman (2012) aborda que os brancos são considerados a normalidade e, por isso, além de possuírem privilégios materiais, sociais, econômicos, entre outros, em relação aos os não brancos, eles consideram que a questão racial é um problema de pessoas não brancas. Por exemplo, é comum situações sociais em que pessoas brancas acham que quem precisa resolver todos os problemas raciais no país são os movimentos negros brasileiros. Além do mais, a autora ainda aborda que:

Na sociedade brasileira, os indivíduos, querendo ou não, são classificados racialmente logo ao nascerem. Nos classificados socialmente como brancos recaem atributos e significados positivos ligados à identidade racial à qual pertencem, tais como inteligência, beleza, educação, progresso etc.” (p. 27)

Nesse sentido, os privilégios brancos no país estão sempre em evidência na mídia, principalmente devido a maioria de papéis de poder que personagens brancos representam nas produções audiovisuais. Já as personagens negras, por exemplo, são quase raras e representadas de forma preconceituosa e estereotipada, na maioria das vezes.

De acordo com Solange Couceiro (2000/2001), as telenovelas se baseiam na verossimilhança, que funciona como um pacto junto ao público que já espera uma personagem negra em uma função subalterna. Quando essa personagem interpreta outros papéis, para além da subalternidade, isso causa incômodo no público. Couceiro também aponta que um argumento recorrente de diretores é que não há "bons atores negros". Esse argumento, além de racista, só reforça os privilégios da branquitude, onde a "concepção estética e subjetiva da branquitude é, dessa maneira, supervalorizada em relação às identidades raciais não brancas." (SCHUCMAN, 2012, p. 27). Nesse ponto, é importante ressaltar também o porquê de não haver 
uma princesa ou rainha negra nas representações audiovisuais quando eu era criança: há sim um racismo na mídia e também um racismo estrutural que impede, na maioria das vezes, que pessoas negras ocupem cargos de poder seja na sociedade ou nas representações. Além do mais, personagens da realeza midiática reforçam um padrão de beleza europeu e, muitas vezes, pessoas negras não são vistas como belas, como de 'boa aparência', principalmente por não serem pertencentes ao padrão de beleza da branquitude, por exemplo.

\section{Representatividade}

Segundo Sandra Roza (2018),

a representação leva à representatividade, que é um processo de uma presença maior de representações sobre grupos sociais e de identificação destes com personagens sociais ou midiáticos que se assemelham a eles, seja de maneira física, cultural, ideológica, de gênero, entre outras. (p. 31)

Se ver em uma tela de televisão, cinema, celular ou computador também é importante para construção de identidades. E até mesmo para se entender e conhecer outras identidades. Entretanto, ainda é frequente na mídia representatividades estereotipadas, isto é, há uma representatividade de identidades nas produções, contudo elas ainda carregam estereótipos e papéis subalternizados. No meu Trabalho de Conclusão de Curso (TCC) em que faço uma análise da primeira princesa negra de animação da Disney, A Princesa Tiana, foi possível observar que ela exerce uma representatividade negra na Linha Princesas Disney ${ }^{3}$, em que a maioria das princesas são brancas. Porém, a Princesa Tiana é construída e representada com base em vários estereótipos sobre as mulheres negras. Já a primeira princesa negra da Disney, a Cinderella, do filme homônimo de 1997, possui semelhanças à Tiana e também reforça mitos

\footnotetext{
3 "Linha comercial de princesas, fundada em 2002, composta por 12 princesas fílmicas: Branca de neve (1937), Cinderela (1950), Aurora (A Bela adormecida - 1959), Ariel (A pequena sereia - 1989), A bela e a fera (1991); Jasmine (Aladdin -1992); Pocahontas (1995); Mulan (1998); Tiana (A princesa e o sapo - 2009); Rapunzel (Enrolados - 2010), Merida (Valente - 2012 ) e Moana (2016).” (ROZA, 2018, p. 60)
} 


\section{Revista Docência e Cibercultura}

e a subalternidade das mulheres negras. Em Cinderela (1997) há uma rainha negra, a Rainha Constantina, interpretada por Whoopi Goldberg, que possui poucas aparições e falas na narrativa. Em vista disso, percebe-se que esses filmes da Disney exercem sim uma representatividade negra, seja de princesas ou rainhas, no entanto a empresa está mais preocupada em obter lucros e "vender" a ideia de que realiza representatividade negra na realeza, por exemplo, do que representar personagens negras sem ser de forma estereotipada. (ROZA, 2018)

Outro ponto importante para se pensar também é a questão de que a representatividade pode ser subjetiva. Por exemplo, diante de um filme, alguém pode dizer que o personagem do filme o representa, já outra pessoa pode dizer que o personagem não o representa. E isso é normal devido cada pessoa possuir a sua identidade pessoal subjetiva. Dessa forma, 'se ver e se reconhecer' em um personagem, por exemplo, nem sempre vai ser algo absoluto na representatividade, principalmente devido às subjetividades de cada identidade, que as representações audiovisuais não buscam representar ou quando representam, fazem isso de forma estereotipada e preconceituosa. Vale destacar também que, segundo as discussões de Baumam nesse artigo, se pode ter várias identidades diferentes. Dessa forma, um produto audiovisual pode representar uma dessas identidades, o que pode fazer com que o indivíduo se sinta representado. Por exemplo, pessoas negras podem se identificar com personagens negras por elas se assemelharem a elas fisicamente ou por terem uma história parecida, ou uma história que amplia as possibilidades de atuação de uma pessoa negra na sociedade, como em empregos e posições sociais que vão além da subalternidade, por exemplo.

\section{Metodologia}

A fim de realizar esse trabalho foi feito, primeiramente, uma revisão bibliográfica da disciplina de Cultura e Identidade na Comunicação com o objetivo de escolher as obras trabalhadas que se aproximam do tema deste artigo. Em seguida, foi realizado também um levantamento bibliográfico nos anais dos 4 principais sites de eventos de comunicação 


\section{Revista Docência e Cibercultura}

brasileiros: Compós ${ }^{4}$, SBPJOR $^{5}$, Intercom ${ }^{6}$ e Alcar $^{7}$. Nas buscas, foram pesquisadas as palavras-chave: gênero, raça, feminismo negro e videoclipes. Além disso, foram escolhidos os anos de 2017, 2018 e 2019. Foram encontrados 34 artigos, porém desses foram selecionados os 12 que estão mais próximos a esse artigo.

Para a realização deste artigo, decidiu-se analisar 5 videoclipes: "Menina Pretinha”, Mc Soffia; “Ouça-me Rmx”, Tássia Reis; “É o poder”, Karol Conká (cantoras nacionais); "Moment 4 Life", Nicki Minaj e "Love on the brain", Rihanna (cantoras internacionais). No fim, a maioria das cantoras escolhidas são rappers, mas isso acabou sendo uma coincidência devido o conhecimento da autora sobre as cantoras e a percepção dos videoclipes em que elas se afirmam ou vestem de rainhas, umas das motivações para a realização desse trabalho.

Já para analisar os videoclipes, foram feitos os prints ${ }^{8}$ das cenas em que as cantoras aparecem ou reforçam a questão de serem rainhas, observando também as letras das músicas. Além disso, todos os videoclipes foram assistidos no Youtube.

Com as cenas e as letras, foi realizada uma análise do discurso com o objetivo de observar e analisar o que poderia estar implícito e explícito nas produções. Segundo Jorge Pedro Sousa (2006), a finalidade de uma análise do discurso é desvelar a "substância de um discurso entre o mar de palavras que normalmente um enunciado possui e fazer inferências entre essa substância e o contexto em que o discurso foi produzido.” (p.660)

\footnotetext{
${ }^{4}$ https://www.compos.org.br/

${ }^{5}$ http://www.sbpjor.org.br/

${ }^{6} \mathrm{http}: / / \mathrm{www}$. portalintercom.org.br/

${ }^{7}$ http://www.ufrgs.br/alcar/links

${ }^{8}$ Captura de tela, em que é possível tirar uma foto da tela do computador, celular, tablet, entre outros.
} 


\section{Análise}

\section{Rainha desde criança: Mc Soffia}

A rapper Soffia Gomes da Rocha Gregório Corrêa, a Mc Soffia, tem 15 anos e desde criança canta músicas que ressaltam a beleza negra, resgatam a ancestralidade afro-brasileira e que questionam as questões raciais no país. Em 2016, Mc Soffia lançou o clipe da música "Menina Pretinha", composta pela cantora, Denna Hill e James Bantu. Gravado em Pedra do Sal, no Rio de Janeiro, o videoclipe apresenta somente crianças negras, sendo a maioria de meninas entre 5 e 8 anos de idade. Todas elas estão com os cabelos crespos soltos, laços e turbantes coloridos. Nas mãos, as meninas seguram makenas africanas, bonecas negras.

MC Soffia em "Menina Pretinha" realiza diversos questionamentos sobre sentir orgulho de ser negra e das suas raízes, por exemplo. Além disso, no trecho: Menina Pretinha, exótica não é linda. Você não é bonitinha. Você é uma Rainha!, sempre ao cantá-lo e falar rainha, a rapper levanta o braço com o punho fechado, como na imagem abaixo, a fim de mostrar resistência, força e luta, por exemplo, no trecho em que a rapper fala: Sou criança sou negra, também sou resistência. Racismo aqui não. Se não gostou paciência. Observa-se que a rainha que a rapper afirma e representa está relacionada a uma posição de poder e também da valorização da beleza negra, principalmente devido ela ressaltar que "exótica não é linda". Nesse sentido, vale destacar também que pessoas negras costumam ser vistas como exóticas, com uma beleza exótica. Segundo Tatiana Gerhardt (2019), a ideia de que pessoas negras são exóticas começou a surgir quando os europeus chegaram à África e viram ali uma cultura diferente da sua. Por ser diferente, os europeus a classificaram como exótica. Infelizmente, ainda essa ideia está presente na sociedade e é, muitas vezes, reproduzida pela mídia. MC Soffia, ao cantar, "exótica não é linda" propõe também uma reflexão para as meninas negras e para o meio social que as elogiam como exóticas, sendo que isso não é um elogio, muito menos algo que esteja relacionado a beleza delas. Já "Você não é bonitinha. Você é uma Rainha!" é uma forma de elevar a autoestima das meninas negras a fim de mostrar que elas são belas com uma beleza que representa poder, principalmente devido a palavra "rainha" está ligada a riquezas e beleza, por exemplo. 


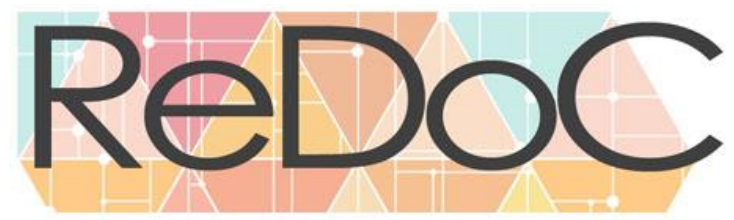

Revista Docência e Cibercultura

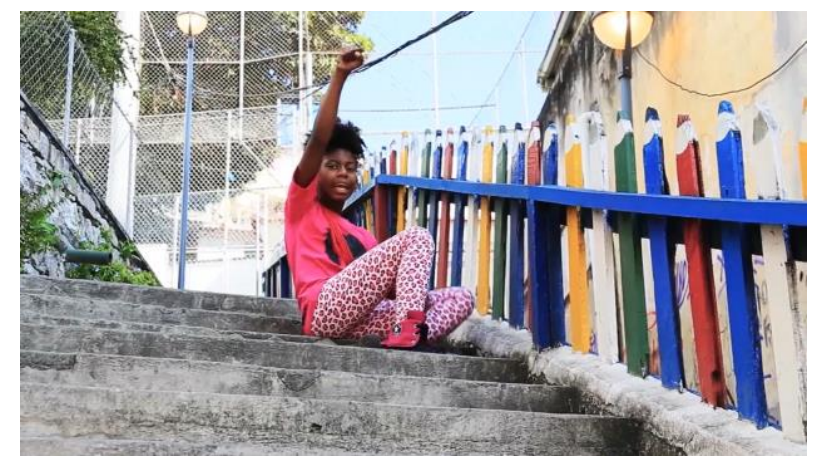

Mc Soffia cantando trecho de "Menina Pretinha"

Fonte: Reprodução da autora

No mais, a ideia de identidade presente em 'Menina Pretinha' se refere à identidade racial negra, principalmente nas reflexões da música sobre o orgulho em ser negra e ter o cabelo crespo, que a cantora enfatiza, e nos resgates históricos que ela faz, por exemplo: Africana, como história de griô, sou negra e tenho orgulho da minha cor/ O meu cabelo é chapado, sem precisar de chapinha. Dessa forma, percebe-se que a representação que a MC Soffia faz é de mostrar uma menina negra empoderada que reconhece a sua história, que se afirma como linda e uma rainha, ao mesmo tempo que também luta contra o racismo. Desse modo, a representatividade que a MC Soffia pretende em 'Menina Pretinha' é de fazer com que outras meninas negras também percebam o poder que também têm e do quanto são lindas, podendo ser também uma personagem da realeza mesmo que ainda haja uma baixa representatividade de meninas negras, como princesas ou rainhas nas produções audiovisuais: Você não é bonitinha, você é uma Rainha.

\section{"Sangue de Rainha": Tássia Reis}

A rapper Tássia Reis aborda o racismo, feminismo negro, empoderamento, silenciamento da mulher negra, entre outras questões em suas músicas. Em 2018, Tássia lançou o videoclipe da música "Ouça-me Rmx", composta por ela. Na produção, a artista faz um protesto sobre a questão do silenciamento da mulher negra: Ouça o meu grito invadindo os teus 


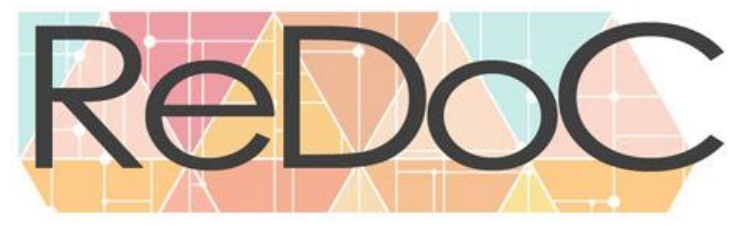

Revista Docência e Cibercultura

ouvidos. Tomando a sua casa e tocando lá no seu radin'. Se o que eu digo lhe fizer algum sentido. É porque o sangue de Rainha Nzinga ainda corre em mim.

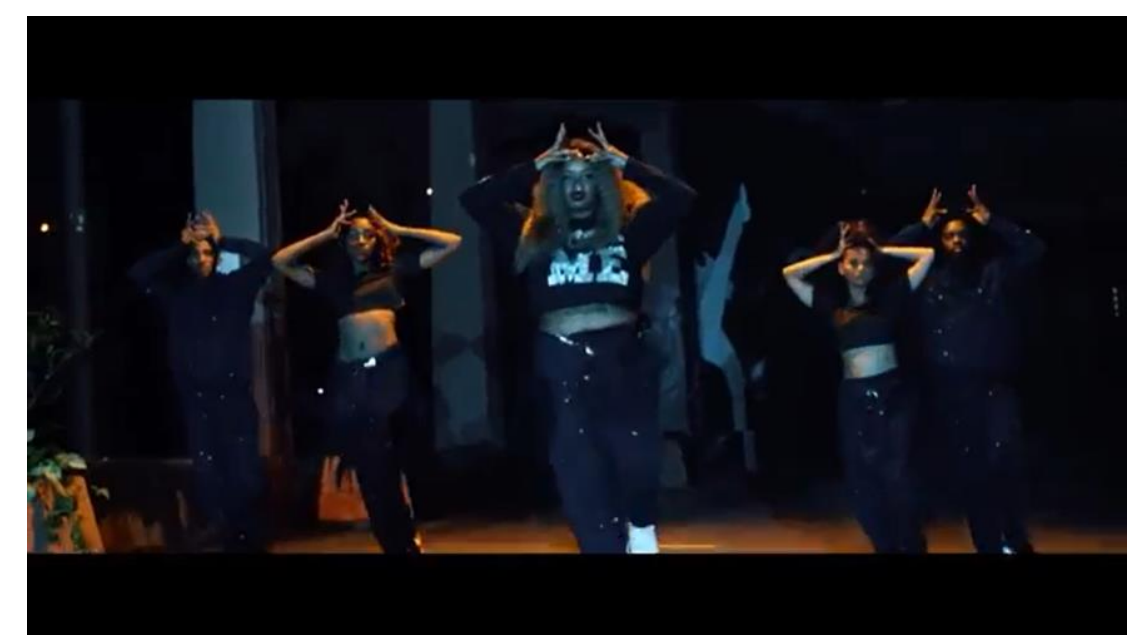

Tássia reis cantando trecho de "Ouça-me Rmx"

Fonte: Reprodução da autora

Ao falar "sangue de Rainha Nzinga", a cantora e seus 4 bailarinos aproximam as mãos da cabeça, a fim de representar uma coroa (imagem acima). Observa-se que ao tratar da questão do silenciamento, Tássia resgata a sua ancestralidade ao falar da Rainha Negra Nzinga ${ }^{9}$ e também mostra a posição de poder que uma rainha possui, principalmente para ser ouvida. Conforme Roza (2018) “O silenciamento de mulheres negras é algo histórico-social e evidencia relações de poder.” (p.81). Esse silenciamento, por exemplo, também estava presente no início dos movimentos feministas europeu e estadunidense, onde somente mulheres brancas e ricas podiam falar. Entretanto, esse silenciamento é intencional, principalmente devido haver "um medo apreensivo de que, se o(a) colonizado(a) falar, o(a) colonizador(a) terá que ouvir e seria forçado(a) a entrar em uma confrontação desconfortável com as verdades do 'Outro'." (KILOMBA, 2016, 176-177)

\footnotetext{
${ }^{9}$ Rainha da Angola que defendeu o seu reino, Ndongo, dos portugueses lutando contra eles, no século XVII.
} 
Vale ressaltar aqui também que Nzinga, por ser mulher, não era vista por muitos em seu reino, o Ndongo, como digna ao trono. Porém, ela sempre lutou e criou estratégias para defendê-lo. Com o sucesso de várias lutas, Nzinga foi ouvida por muitos em seu reino e fora dele, principalmente pelos homens que não acreditavam nela por ela ser uma mulher negra. Ao citar Nzinga, Tássia também pode estar apresentando que o silenciamento das mulheres negras vai além dos seus "reinos", dos lugares em que elas estão, porém elas também querem ter suas vozes ouvida e não mais oprimida ${ }^{10}$, assim como a Rainha Nzinga.

Portanto em 'Ouça-me Rmx', a ideia de identidade que a cantora enfatiza é também a identidade racial negra, principalmente quando ela cita a sua ancestralidade por meio da Rainha Nzinga e por falar sobre questões que atravessam a mulher negra, como o silenciamento. Além disso, ao falar de Nzinga, a cantora se afirma e se autorrepresenta como uma rainha, quando faz uma coroa com a mãos. Dessa forma, a representatividade que a Tássia Reis provoca é de mostrar uma mulher negra que deve e quer ser ouvida e respeitada, assim como a Rainha Nzinga, conforme mencionado no parágrafo acima.

\section{“Quem disse que isso aqui não era para mim se equivocou”: Karol Conká}

A rapper Karol Conká também aborda em suas músicas racismo, empoderamento, superação e questões sociais. Em 2016, Karol lançou o videoclipe da música "É o poder", composta pela cantora, Duani e Doncesão. Na produção, Karol usa diversos figurinos e se apresenta em uma posição de poder, falando de como as pessoas se assustam com ela nessa posição. Por exemplo, nesse trecho: Sociedade em choque eu vim pra incomodar. Aqui o santo é forte, é melhor se acostumar. Quem foi que disse que isso aqui não era pra mim se equivocou. Fui eu quem criei, vivi, escolhi, me descobri e agora aqui estou. Em um dos momentos do videoclipe, a cantora está com uma peruca branca, óculos escuros, roupas e um objeto dourado na cabeça, semelhante a uma coroa. Então, Karol canta: É o poder. O mundo é de quem faz.

\footnotetext{
${ }^{10}$ Trecho da música “Ouça- me Rmx”, da Tássia Reis.
} 


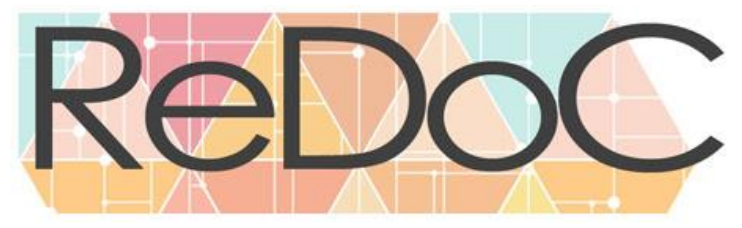

Revista Docência e Cibercultura

Embora a rapper não se refira a questão de ser rainha, ela apresenta a questão de ser uma mulher negra na posição de poder e o tendo, além de evidenciar também uma mulher negra no rap que, ainda é um espaço machista e com maior visibilidade para os homens. Além do mais, ao dizer Quem foi que disse que isso aqui não era pra mim se equivocou, Karol enfatiza algo muito comum na sociedade: o estranhamento ao ver uma pessoa negra em uma posição de poder, principalmente uma mulher negra; e a dúvida que ela possa ocupar esse lugar. Eu, por exemplo, já passei e passo por muitas situações assim. Ao me formar em jornalismo, vejo a todo momento diversas pessoas não acreditarem que sou jornalista e de duvidarem que sou eu que escrevo os meus textos e trabalhos acadêmicos.

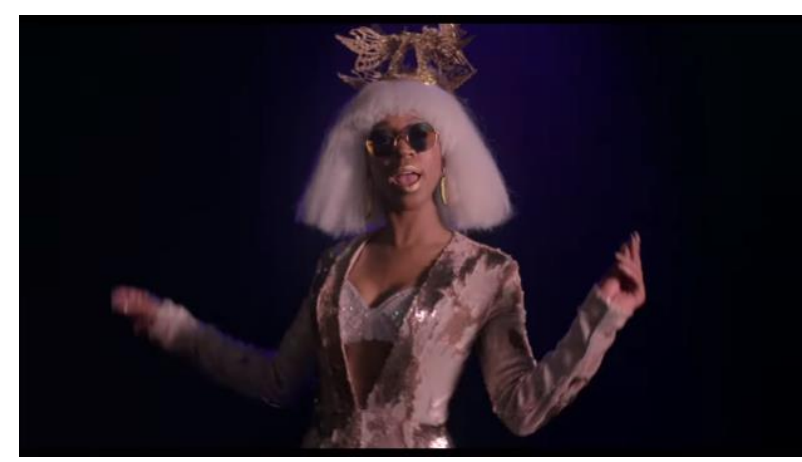

Karol Conká cantando trecho de "É o poder"

Fonte: Reprodução da autora

Portanto em 'É o poder', a ideia de identidade que a cantora enfatiza é de uma identidade racial, principalmente por Karol Conká mostrar os estranhamentos que as pessoas têm quando uma mulher negra está em uma posição de poder. Nesse sentido, a representação que a cantora faz é de uma mulher negra bem-sucedida, poderosa e que se impõe: não aceito cheque, já te aviso, não me testel Se não tá no meu lugar, não fale meu. Nesse último trecho, fica evidente a questão do lugar de fala e de como ele deve ser respeitado pelas pessoas que insistem em falar, sem nunca ouvir quem pertence a determinado grupo, por exemplo. Aqui, fica explícita a representatividade que a Karol Conká propõe: de uma mulher negra que fala por si própria. E falar por si evidencia também uma relação de poder, principalmente devido muitas mulheres negras serem silenciadas ou gritarem para serem ouvidas, como aponta a Tássia Reis acima. 


\section{Rainhas Pop: Nicki Minaj e Rihanna}

As cantoras Nicki Minaj e Rihanna são conhecidas mundialmente na música Pop. Com músicas que falam sobre relacionamentos amorosos, sexo, feminismo, entre outros temas. Elas também questionam a posição de poder que possuem, seja financeiro ou artístico. Além disso, são cantoras que possuem mais de um videoclipe em que estão vestidas ou com acessórios que remetem a rainhas, na maioria das vezes, com base em realezas europeias. É válido destacar também que midiaticamente elas costumam, ser chamadas de "queens" (rainhas) ou "princess" (princesas).

Onika Tanya Maraj, a Nicki Minaj, também rapper, lançou em 2011, o videoclipe da música "Moment 4 life""11, composta pela cantora, Drake, Nikhil Seetharam e T-Minus, com a participação do rapper Drake. A produção se inicia apresentando um livro de contos de fadas escrito "Era uma vez, um rei chamado Nicki. Um dia, enquanto estava sentado no seu trono, ela recebeu uma visita encantada de sua fada madrinha. Ela o lembraria do momento para a vida."12 Em seguida, aparece a cantora sentada, com um vestido azul, em frente uma penteadeira. Depois, aparece a fada madrinha, que é a própria Nicki, que se chama Martha. As duas conversam que momentos como esse costumam terminar meia-noite, mas Martha diz que esse momento será eterno para a Nicki. Ainda a fada madrinha faz aparecer, com a sua varinha mágica, um sapato brilhante para a cantora. Após calçar os sapatos, Nicki vai para uma festa em uma mansão. Lá, a cantora anda sorridente no meio dos outros convidados enquanto é observada incessantemente pelo Drake. No fim, os dois aparecem do lado de fora da mansão olhando uma queima de fogos de artifícios. Ele está com um terno preto e ela com um vestido

\footnotetext{
${ }^{11}$ Em "Moment 4 Life", o número 4 em inglês se ler "Four" com a mesma pronúncia da palavra "For", que significa "Para" em português. Assim, o nome da música fica: "Moment For Life". Em tradução livre significa "Momento para a vida."

12 Tradução da autora. Trecho no idioma original: “Once upon a time there lived a king named Nicki. One day, while sitting on her throne, she received an enchanting visit from her fairy Godmother. She would remember that moment for life."
} 
branco, um buquê de flores e uma peruca rosa. Eles se beijam e o relógio marca meia-noite. Eles se casam como afirma o Drake no trecho: Eu e a Nicki nos casamos hoje. Assim, observa - se que as cenas se assemelham muito ao conto de fadas da Cinderela ${ }^{13}$.

Além disso, na música, a cantora fala "queria que esse momento durasse a vida toda" e de como Hollywood não irá mudar quem ela é. Há também dois trechos que se remetem à realeza: Nesse momento, eu sou um rei. (...) Coloque em todos os lugares que vou me aposentar com o anel. E com a coroa, sim! Com base na letra da música e no videoclipe, percebe-se que a cantora faz uma música sobre superação, ascensão social, sucesso e sobre o lugar em que ocupa. Ao falar que irá se aposentar com a coroa pode ser uma forma de mostrar que ela possui poder e que esse poder exige respeito: Sorrio pros inimigos pena que vocês não podem me derrubar. Não estamos sendo arrogantes, só estamos nos vingando. Melhor crer que quando acabar esse momento será investigado. Eu não sei, mas essa noite me lembra de tudo o que eles me privaram. Vamos brindar é uma festa cada vez que nos reunimos. Temos feito tudo o que eles acham que podem fazer. A grandeza é o que queremos beirar. Com base nesse trecho acima, é possível ver que a cantora também relaciona esse momento com questões raciais, de gênero e classe, principalmente devido ela ter se ascendido socialmente, mas ao mesmo tempo ter sido privada (e ainda pode ser privada) de muitas coisas por ser uma mulher negra e rapper. Ao mesmo tempo, a cantora apresenta no videoclipe o seu próprio conto de fadas. No caso, se ela não teve uma representatividade nessas histórias de rainhas, reis, príncipes e princesas, é ela que está criando essa representatividade agora com a sua própria história: essa noite me lembra de tudo o que eles me privaram. Vale destacar também que a Nick fala que é um rei. Para Judith Butler (2003), o gênero é amplo e construído socialmente. Nesse sentido, quando

\footnotetext{
13 No conto de fadas da Cinderela, dos Irmãos Grimm, uma mulher vive com suas duas irmãs e a madrasta.Cinderela é a empregada da casa e precisa fazer tudo o que elas pedem. Quando elas são convidadas para um baile, Cinderela é impedida de ir. Mas aparece para ela uma fada madrinha que faz aparecer, com a sua varinha mágica, um vestido de festa para ela, transforma uma abóbora em carruagem e ratos em cocheiros, que guiarão a carruagem. Ainda, a fada madrinha faz a aparecer um sapato de cristal para a Cinderela, e avisa que ela só pode ficar no baile até meia-noite. Cinderela vai ao baile e dança com o príncipe. Quando o relógio marca meia-noite, Cinderela sai correndo do palácio e esquece um de par do seu sapato de cristal. O príncipe corre atrás dela, mas só encontra o sapato. Assim, ele começa a busca pelo reino para saber quem é a dona do calçado. Por fim, ele encontra Cinderela e se casa com ela.
} 
Nick fala que é um rei, ela também mostra que pode fazer escolhas para a sua identidade de gênero e ser um rei, sem precisar está vestida como um e nem de ser um homem biologicamente, por exemplo.

Portanto em 'Moment 4 life', a ideia de identidade que a cantora enfatiza é de uma identidade racial, por ser uma mulher negra no rapper, mas também da identidade de gênero quando ela faz referência a ser um rei, como apresentado no parágrafo acima. Nesse sentido, a representação que a cantora faz é de uma mulher negra bem-sucedida, que é uma princesa (e também um rei) poderosa, que superou tudo que passou na vida, seja financeiramente, como rapper ou como mulher negra. Desse modo, a representatividade que Nick Minaj enfatiza, principalmente, é de uma mulher negra como princesa, vivendo o conto de fadas da Cinderela.
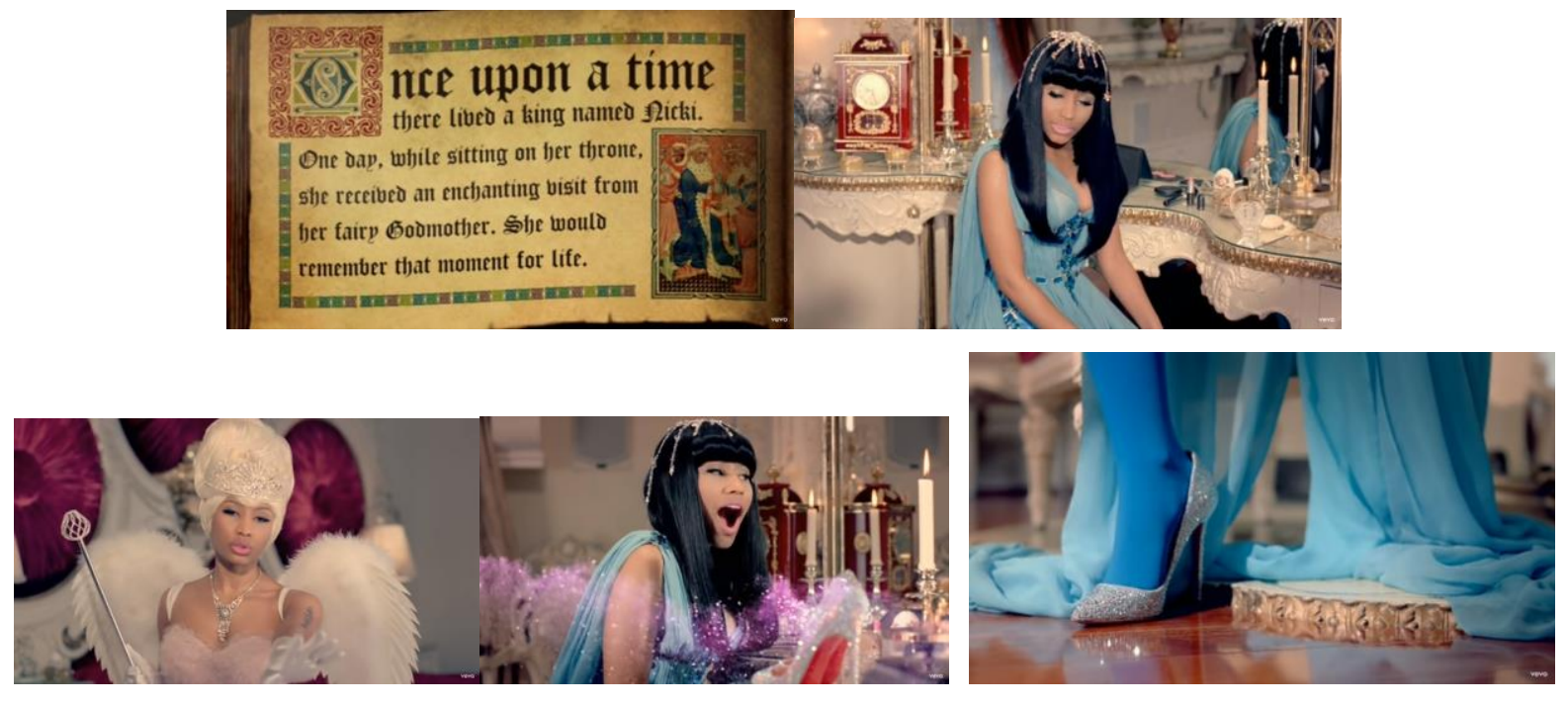


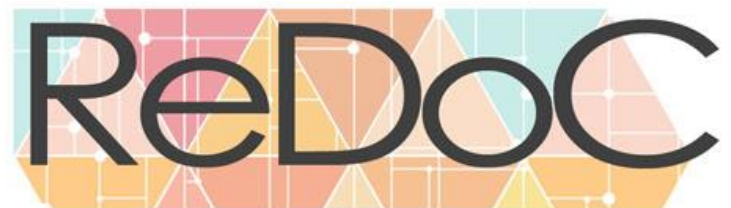

\section{Revista Docência e Cibercultura}
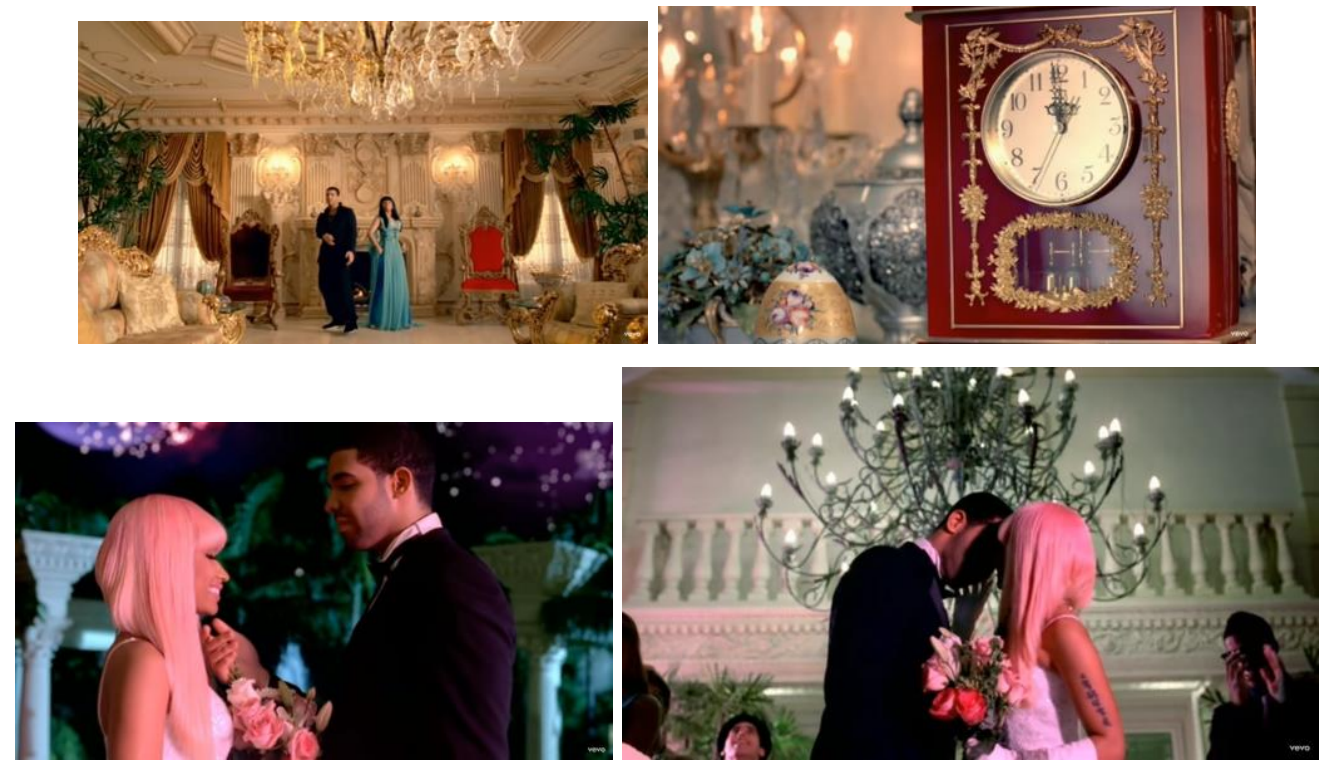

Sequência de imagens do videoclipe descritas no texto: Livro de contos de fadas, Nicki sentada em frente a penteadeira, a fada madrinha faz um sapato brilhante aparecer, Nicki calça o sapato, Nicki e Drake cantando na festa com duas cadeiras que simbolizam tronos atrás deles, o relógio marca meia-noite, Nicki e Drake se beijam e se casam.

Fonte: Reprodução autora.

Robyn Rihanna Fenty lançou em 2016, o videoclipe da música "Love on the brain" composta pela cantora, Joseph Angel e Fred Ball. Na música, a cantora fala sobre um amor platônico. Já durante o videoclipe, aparece uma menina negra com uma coroa dourada com escritos em braile sob a cabeça, tampando os olhos. Essa menina entrega a coroa à Rihanna que a coloca na cabeça e termina o videoclipe com ela. Ainda na produção aparece o busto dourado da Rainha Nefertiti, uma rainha egípcia. Love on the brain é uma das músicas que compõe o álbum ANTi (2016), da cantora, que possui encartes em braile, nesse sentido Rihanna foi a primeira cantora a ter um albúm com encartes em braile ${ }^{14}$. Segundo Gabriela Zocchi (2015),

${ }^{14}$ ZOCCHI, Gabriela. Rihanna será primeira artista a lançar um álbum inteiramente em braile. Capricho. 17 Ago. 2016. Disponível: .https://capricho.abril.com.br/famosos/rihanna-sera-a-primeira-artista-a-lancar-umalbum-inteiramente-em-braile-2/. Acesso em: 16 Jun. 2019 


\section{Revista Docência e Cibercultura}

do site da Revista Capricho, a menina com a coroa é a cantora Rihanna na infância e "a coroa em seus olhos simboliza "o poder que cega as pessoas para as coisas realmente importantes na vida". ${ }^{15 "}$. Com base nessas informações, percebe-se uma cantora que se via como rainha/princesa quando criança e que se coroa novamente já adulta. Seria uma princesa que se tornou uma rainha? Esse momento apresenta também dois pontos interessantes: uma menina negra com uma coroa e uma mulher negra com uma coroa. Embora na letra da música Rihanna não diga nada relacionado a isso, a cena é significativa e provocativa. Vale destacar também que em um outro momento do videoclipe aparece o busto da Nefertiti. Historicamente há divergências sobre se ela seria negra ou não. Além disso, o Egito pertence ao continente africano, porém o país, muitas vezes, é visto midiaticamente como isolado do continente. Nisso também ocorre o apagamento e embranquecimento dos egípcios, como o da Rainha Nefertiti. A presença dela no videoclipe pode ser uma crítica à visão embranquecida dela mostrando também que ela não é uma rainha branca, mas egípcia africana. Além do mais, se a coroa sobre os olhos da menina significa um poder que cega, essa crítica propõe também pensar até que ponto o poder é mais importante na vida, seja financeiro ou artístico. Ao colocar a coroa na cabeça, Rihanna pode está tentando mostrar que é importante pensar sobre esse poder e tirar ele dos olhos, buscando assim um equilíbrio entre o olhar e a razão (cabeça). Com a coroa na cabeça, é possível enxergar e perceber o mundo além do poder.

Portanto em 'Love on the brain', a ideia de identidade que a cantora enfatiza é de uma identidade racial, por ser uma mulher negra e também por resgatar a sua ancestralidade por meio do busto dourado da Rainha Nefertiti, rainha egípcia africana. Nesse sentido, a representação que a cantora faz é de uma mulher negra rainha/princesa, principalmente por ela está com uma coroa dourada na cabeça. Desse modo, a representatividade que Rihanna enfatiza, principalmente, é de uma mulher negra poderosa e rainha, ao mesmo tempo em que apresenta

\footnotetext{
${ }^{15}$ Disponível em: Acesso em: https://capricho.abril.com.br/famosos/rihanna-sera-a-primeira-artista-a-lancar-umalbum-inteiramente-em-braile-2/. 16 Jun. 2019
} 


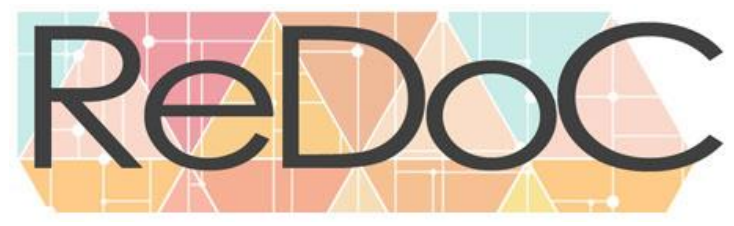

Revista Docência e Cibercultura

uma menina negra com uma coroa, o que remeteria à representatividade de uma menina como princesa, por exemplo.
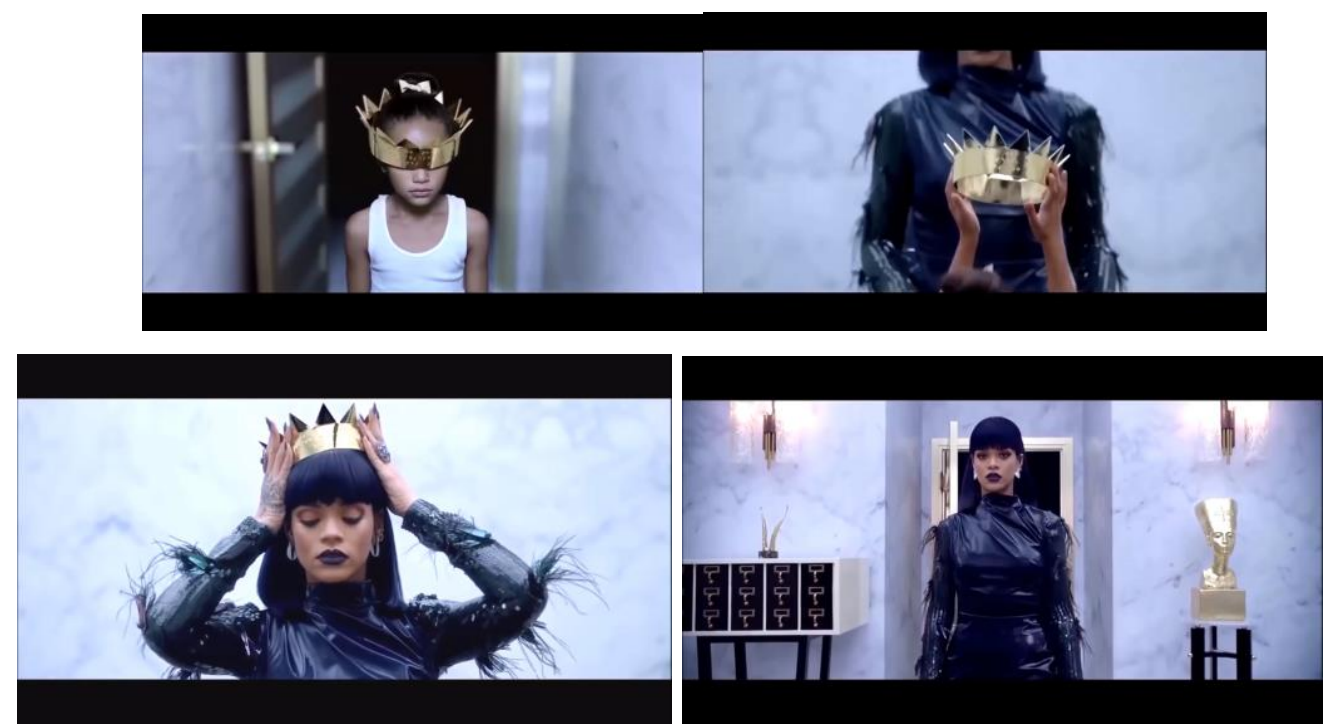

Sequência: Menina tira a coroa da sua cabeça entrega à Rihanna e essa a coloca na cabeça, busto dourado de Nefertiti ao lado da Rihanna.

Fonte: Reprodução autora

\section{Considerações Finais}

Identidade, representação e representatividade são palavras que se conectam. Por meio das análises dos videoclipes foi possível perceber como a representatividade pode ajudar no processo de construção de identidades de uma pessoa e como ela propõe novas formas de ser quem ela é com outras formas de representação sobre ela. Por exemplo, ainda há diversas representações de mulheres negras de forma estereotipada na mídia. Entretanto, é importante perceber como artistas negras propõem outras representações sobre elas que buscam questionar, trazer representatividade e reconhecimento. 
Mc Soffia, Tássia Reis, Karol Conká, Nicki Minaj e Rihanna, cada uma, de uma forma, busca se afirmar como mulheres da realeza, seja nas letras das músicas, nos gestos ou nos figurinos dos videoclipes. Elas estão lá questionando, incomodando e mostrando que podem estar em posições de poder e ser rainhas. Isso pode influenciar muito os fãs dessas cantoras. $\mathrm{E}$ principalmente, inspirar meninas, como eu, que nunca viram uma princesa ou rainha negra quando eram crianças.

Mas Nicki Minaj e Rihanna não deveriam representar rainhas africanas como Mc Soffia e Tássia Reis fizeram? Com certeza não, uma vez que com a globalização as pessoas podem possuir diversas identidades, não se limitando somente a uma identidade racial, por exemplo. Além do mais, quando essas cantoras se vestem de rainhas com base em rainhas europeias, é algo que também leva a refletir sobre as relações de poder: "e se quem foi escravizado estivesse no trono?" Essa pergunta pode gerar várias inquietações por meio do discurso de apropriação cultural, como forma de tentar impedir que mulheres negras possam se auto representarem e se afirmarem como rainhas que remetem a realezas europeias.

Além disso, acredito que as representações que as cantoras apresentadas neste artigo fazem são importantes e possuem alcances mundiais. Muitas delas também podem ter tido os mesmo questionamentos (ou similares) que eu na infância, e por isso buscaram se auto representarem como rainhas. Além do mais, a posição que cada uma dessas cantoras ocupa é importante e reforça o que a Karol Conka diz: Quem foi que disse que isso aqui não era pra mim se equivocou.

\section{Referências Bibliográficas}

ALCÂNTARA, Fabiano. Aposta da nova música brasileira, Karol Conká lança 'É o poder', ouça. 4 Dez. 2015. Disponível em: http://www.virgula.com.br/musica/aposta-da-novamusica-brasileira-karol-conka-lanca-e-o-poder-ouca/.Acesso em: 16 Jun. 2019 
BAUMAN, Zygmunt. Identidade: entrevista a Benedetto Vecchi. Rio de Janeiro: Jorge Zahar Editor, 2005

BUTLER, Judith. Sujeitos do sexo/gênero/desejo. In: Problemas de gênero: feminismo e subversão da identidade. Rio de Janeiro: Civilização Brasileira, 2003. p. 17-33

COUCEIRO, Solange. A personagem negra na telenovela brasileira: alguns momentos. Revista USP, São Paulo, n. 48, p. 88-99, dez./fev. 2000-2001. Disponível em: https://www.revistas.usp.br/revusp/article/download/32894/35464/. Acesso em: 9 mar. 2019.

Conheça MC Soffia, menina que é "pura rima" aos 11 anos. EBC. 13 Nov. 2015. Disponível em: http://www.ebc.com.br/infantil/2015/11/conheca-mc-soffia-menina-que-epura-rima-aos-11-anos. Acesso em 13 Jun. 2019

É o poder. Karol Conká. Vagalume. Disponível em: https://www.vagalume.com.br/karolconka/e-o-poder.html. Acesso em: 16 Jun. 2019

É o poder. Karol Conka. 2016. Youtube. Disponível em: https://www.youtube.com/watch?v=kOSQngZjvdc . Acesso em: 16 Jun. 2019

FRAZÃO, Dilva. Rihanna. Ebiografia. 26 Jun. 2015. Disponível em:https://www.ebiografia.com/rihanna/ .Acesso em: 16 Jun. 2019

FERNANDES, Danubia Andrade. A personagem negra na telenovela brasileira: representações da negritude em "Duas caras". 2009. 176 f. Dissertação (Mestrado em Comunicação) - Universidade Federal de Juiz de Fora (UFRJ), Faculdade de Comunicação Social, Juiz de Fora, 2009. Disponível em: <https://repositorio.ufjf.br/jspui/handle/ufjf/3382>. Acesso em: 31 Jul. 2018.

GERHARDT, Tatiana Engel. Curso Imagens para pensar o outro: módulo 2 - A imagem, instrumento de conhecimento do outro ou de interiorização de preconceitos?. Lúmina. Universidade Federal do Rio Grande do Sul. Ed. 2. 2019. Disponível em:https://bit.ly/2JGi3Kf. Acesso em: 24 Jun. 2019 
GERHARDT, Tatiana Engel. Introdução do Curso Imagens para pensar o outro. Lúmina. Universidade Federal do Rio Grande do Sul. Ed. 2. 2019. Disponível em: https://bit.ly/2HCyowX. Acesso em: 14 Mai. 2019

KILOMBA, Grada. A máscara. Tradução de Jessica Oliveira Jesus. Cadernos de Literatura em Tradução, Especial Negritude e Tradução, n. 16, p. 171-180, 2016. Disponível em: <https://www.revistas.usp.br/clt/article/view/115286>. Acesso em: 24 Jun. 2019

Love on the brain. Rihanna. Vagalume. Disponível em: https://www.vagalume.com.br/rihanna/love-on-the-brain-traducao.html. Acesso em: 16 Jun. 2019

Love on the brain. Rihanna. 2016. Youtube. Disponível em: https://www.youtube.com/watch?v=0RyInjfgNc4. Acesso em: 16 Jun. 2019

Love on the brain. Warner Chappell Music. Disponível em: http://www.warnerchappell.com/song-details/WW\%20010450903\%2000/4e48bf48-56e0497b-9ebd-f7deec006e82. Acesso em: 16 Jun. 2019

Menina Pretinha. Mc $2016 . \quad$ Youtube. Disponível em:https://www.youtube.com/watch?v=cbOG2HS1WKo. Acesso em: 16 Jun. 2019

Moment 4 life. Nicki feat. Drake. Vagalume. Disponível em:em:https://www.vagalume.com.br/nicki-minaj/moment-4-life-feat-drake-traducao.html .Acesso:16 Jun. 2019

Nicki Minaj - Moment 4 Life (Clean Version) ft. Drake. 2011. Youtube. Disponível em: https://www.youtube.com/watch?v=D7GW8TYCEG4. Acesso em: 16 Jun. 2019

Nzinga, a rainha negra que combateu os traficantes portugueses. Geledés. 2 Jun. 2015. Disponível em: https://www.geledes.org.br/nzinga-a-rainha-negra-que-combateu-ostraficantes-portugueses/ . Acesso em: 24 Jun. 2019

Ouça-me Rmx. Tássia Reis. 2018. Youtube. Disponível em: https://www.youtube.com/watch?v=ZY6UknkK65k. Acesso em: 16 Jun. 2019

ROZA, Sandra Rita de Cássia. Novas e antigas formas de representar a mulher negra nas telenovelas: uma análise da personagem Raquel, de $O$ outro lado do paraíso. Cad. Gên. Tecnol., Curitiba, v. 12, n. 40, p. 189-

198, jul./dez., 2019. Disponível em: https://periodicos.utfpr.edu.br/cgt. Acesso em: 30 Jul. 2019. 
ROZA, Sandra Rita de Cássia. Quem é Tiana? Construções e representações da primeira princesa negra de animação da Disney. 2018. 127 f. Monografia (Graduação em Jornalismo) - Instituto de Ciências Sociais Aplicadas, Universidade Federal de Ouro Preto, Mariana, 2018. Disponível em: https://www.monografias.ufop.br/handle/35400000/1674. Acesso em: 12 Jun. 2019

SERELLE, Marcio; SENA, Ercio. Crítica e reconhecimento: lutas identitárias na cultura midiática. 2018. Anais eletrônicos...Belo Horizonte: Pontifícia Universidade Católica de Minas Gerais (PUC Minas). p 1-20. 2018. Disponível em: http://www.compos.org.br/data/arquivos_2018/trabalhos_arquivo_B8QBVICAIOHUZPYXE ZYC_27_6386_21_02_2018_15_09_19.pdf . Acesso em: 12 Jun. 2019

SCHUCMAN, Lia Vainer. Branquitude e Raça e Racismo (parcial). In: Entre o "encardido", o "branco" e o "branquíssimo": raça, hierarquia e poder na construção da branquitude paulistana. 2012. 160 f. Tese (Doutorado em Psicologia Social) - Instituto de Psicologia, Universidade de São Paulo, São Paulo, 2012. p. 17-41. Disponível em: http://www.ammapsique.org.br/baixe/encardido-branco-branquissimo.pdf. Acesso em: 12 Jun. 2019.

SODRÉ, Muniz. A identidade como valor. In: Claros e escuros: identidade, povo e mídia no Brasil. 2. ed. Petrópolis, RJ: Vozes, 1999. p. 233-257

SOUSA, Jorge Pedro. Pesquisa comunicacional - 9.6.4 Outras análises do discurso: o caso das narrativas audiovisuais. In: SOUSA, Jorge Pedro. Elementos de teoria e pesquisa da comunicação e dos media. $2^{\mathrm{a}}$ ed. Porto, 2006, p. 716 - 717. Livro eletrônico. Disponível em: http://www.bocc.ubi.pt/pag/sousa-jorge-pedro-elementos-teoria-pequisa-comunicacaomedia.pdf. Acesso em: 26 Jun. 2018.

ZOCCHI, Gabriela. Rihanna será primeira artista a lançar um álbum inteiramente em braile. Capricho. 17 Ago. 2016. Disponível: .https://capricho.abril.com.br/famosos/rihannasera-a-primeira-artista-a-lancar-um-album-inte. Acesso em: 30 Jul. 2019 